Fetal Diagnosis and Therapy

\title{
Maternal Risk Factors and Perinatal Characteristics in Congenital Diaphragmatic Hernia: A Nationwide Population-Based Study
}

\author{
Carmen Mesas Burgos ${ }^{a}$ Henrik Ehrén ${ }^{a}$ Peter Conner ${ }^{b}$ Björn Frenckner ${ }^{a}$

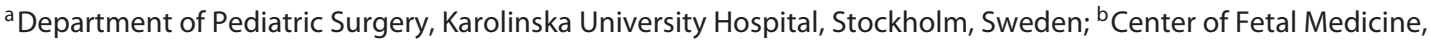 \\ Karolinska University Hospital, Stockholm, Sweden
}

\section{Keywords \\ Congenital diaphragmatic hernia $\cdot$ Risk factors . \\ Epidemiology}

\begin{abstract}
Background: The etiology of congenital diaphragmatic hernia $(C D H)$ remains poorly understood. We hypothesize that environmental factors play an important role in the development of CDH. Aim: The objective of this study was to investigate associated maternal risk factors in pregnancies with $\mathrm{CDH}$. Material and Methods: The study was a nationwide, population-based prospective case-control study consisting of a cohort of newborn children entered into the records of pregnant women receiving antenatal care in Sweden, registered in the Medical Birth Registry during the period from January 1, 1982 to December 31, 2015. The study outcome $\mathrm{CDH}$ and the different exposures were assessed through linkage to the Swedish National Patient Registry for both cases and mothers. Results: A total of 972 cases of $\mathrm{CDH}$ were registered into one of the national registries in Sweden between 1982 and 2015. The incidence of neonates with CDH in Sweden from 1982 to 2015 was 3/10,000 live births. The mortality rate during the study period was $31 \%$. Maternal age, ethnicity, parity, exposure to tobacco, BMI, IVF, previous
\end{abstract}

history of spontaneous abortion or intrauterine fetal demise, and coexisting chronic diseases (urinary tract infection, chronic renal disease, pregestational diabetes, epilepsy, asthma, ulcerative colitis, inflammatory bowel disease, or systemic lupus erythematous) were not associated with an increased risk of $\mathrm{CDH}$ in the fetus. There was a significant association between maternal hypertension and the risk of the child being affected by CDH (OR 3.32, 95\% Cl 1.41-7.79, $p=$ 0.01 ). No association was found between preeclampsia and $\mathrm{CDH}$. Conclusions: Pregestational hypertension is associated with an increased risk of giving birth to a baby with $\mathrm{CDH}$, but no association was observed in pregnancies developing preeclampsia and the occurrence of $\mathrm{CDH}$.

(c) 2019 S. Karger AG, Basel

\section{Introduction}

The etiology of congenital diaphragmatic hernia $(\mathrm{CDH})$ remains poorly understood. The association of $\mathrm{CDH}$ with chromosomal abnormalities, the existence of

This work was presented as an oral presentation at the 37th Annual Meeting of the International Fetal Medicine and Surgery Society, August 7-12, 2018, Bali, Indonesia.

\section{KARGER}

(c) 2019 S. Karger AG, Basel

E-Mail karger@karger.com

www.karger.com/fdt
Carmen Mesas Burgos

Department of Pediatric Surgery, C11:33

Eugeniavägen 22, Karolinska University Hospital

SE-17176 Stockholm (Sweden)

E-Mail Carmen.mesas.burgos@ki.se 
familiar $\mathrm{CDH}$, and the co-occurrence of $\mathrm{CDH}$ with additional malformations support an underlying genetic etiology [1-3]. However, environmental and endogenous factors also seem to play a critical role. Maternal exposure to tobacco [4], alcohol $[5,6]$, and pregestational diabetes [5], maternal underweight [7], or age [8] have been suggested as potential risk factors for the development of $\mathrm{CDH}$. Most likely, the etiology is multifactorial. With an incidence of only $3 / 10,000$ live births [9-12], research concerning the etiology of $\mathrm{CDH}$ remains elusive.

We hypothesize that environmental factors play an important role in the development of $\mathrm{CDH}$. The aim of this study was to investigate the maternal risk factors and perinatal characteristics of $\mathrm{CDH}$ pregnancies in a nationwide, population-based study undertaken in Sweden.

\section{Materials and Methods}

\section{Study Design}

This was a nationwide, population-based prospective nested case-control study within a cohort of newborn children of women registered in the records of antenatal care clinics in Sweden and the Medical Birth Registry (MBR) during the observational period from January 1, 1982 to December 31,2015. The outcome of CDH and the study exposures were assessed through linkage to the Swedish National Patient Registry (NPR) for both cases and their mothers. All Swedish residents are assigned a unique 10-digit personal identification number at the time of birth or following immigration, which enables linkage among the different national registries and a complete follow-up, which was undertaken in the present study.

\section{Registers}

The Swedish National Board of Health and Welfare started the NPR in 1964, which contains prospectively collected information on all hospital admissions in Sweden, including diagnosis and surgical procedures according to the WHO International Classification of Diseases (ICD) system. Since 1987 the register has covered $100 \%$ of the Swedish population. Reporting is good, with less than $2 \%$ of all hospitalizations missing [13].

The MBR contains prospectively collected data on pregnancies and deliveries in Sweden since 1973. Since 1982 more detailed data have been entered into the register, including information on antenatal care, deliveries, and medical examinations of the newborn. Records for only a small percentage of all infants (0.5-3.9\%) are lacking. At the moment, information on prenatal testing is not available. The risk of not identifying a patient using a combination of these registers has been reported as negligible [13].

Outcome Assessment and Definition of Cases and Controls

Eligible case participants of this cohort were children who were born and diagnosed with $\mathrm{CDH}$, whereas control participants without a history of $\mathrm{CDH}$ were randomly sampled from within the cohort and matched for birth year and sex. For each case, 5 controls were randomly chosen. The following codes of the ICD were used to identify the diagnosis of CDH: ICD-9 756.6, ICD-10 Q79.0 and Q79.1.

\section{Assessment of Exposures and Covariates}

Maternal Risk Factors

Exposure data on maternal age, ethnicity, parity, smoking or use of chewing tobacco, BMI, IVF, previously spontaneous abortion or intrauterine fetal demise (IUFD), and coexisting chronic diseases (urinary tract infection, chronic renal disease, pregestational diabetes, epilepsy, asthma, inflammatory bowel disease, systemic lupus erythematous, and chronic hypertension) were prospectively collected in the MBR. Data concerning preeclampsia was collected from the NPR using the codes ICD codes O13, O14, 642D-642F (ICD-9), and O13, O14, O15 (ICD-10).

The maternal age was categorized into 5 groups $(<20,20-24$, $25-29,30-34$, and 35+ years). Data on ethnicity were categorized into 6 groups: Nordic, European (including Russia, excluding the Nordic countries), Asian (including Oceania), African, North American, and South American. Data on maternal smoking or use of chewing tobacco was categorized into non-smokers/tobacco users, 1-9 cigarettes/day, $>10$ cigarettes/day both at the time of conception and in the second trimester. Parity was categorized into 3 groups: 1,2 , or $3+$ children. Maternal BMI was calculated as body weight $(\mathrm{kg})$ divided by the square of the body length $\left(\mathrm{m}^{2}\right)$, and categorized into 5 groups: $<18$ (underweight), 18-24 (normal weight), 25-29 (overweight), 30-34 and 35+ (obese).

\section{Perinatal Characteristics}

Exposure data on the delivery mode, gestational age at birth (GA), birth weight $(\mathrm{Bw})$, gender, Apgar scores, and placental weight $(\mathrm{Pw})$ were obtained from the MBR. A Pw/Bw ratio was calculated. The delivery mode was categorized as vaginal, or elective or emergency Cesarean section (CS). Birth was categorized into small for GA (SGA) or appropriate for GA.

\section{Statistical Analysis}

Possible risk factors for $\mathrm{CDH}$ (maternal age, ethnicity, parity, tobacco exposure, BMI, IVF, previous spontaneous abortion or IUFD, and coexisting chronic diseases) were analyzed using conditional regression models (clogit in $\mathrm{R}$ ) stratifying over the matched pairs. The results are presented as odds ratios (OR) with 95\% CI. All ORs of developing $\mathrm{CDH}$ were calculated using a univariate approach.

The association between $\mathrm{CDH}$ and perinatal characteristics was examined using the Fischer exact test for categorical variables and $t$ test or Mann-Whitney $U$ test for numerical variables. Values of $p<0.05$ were considered to be significant. All statistics were performed in R software version 2.38 (http://CRAN.R-project.org/ package=survival).

\section{Results}

A total of 972 cases of $\mathrm{CDH}$ were registered in one of the national registries in Sweden between 1982 and 2015. As reported earlier [12], the incidence of $\mathrm{CDH}$ in Sweden between 1982 and 2015 was 3/10,000 live births. The 


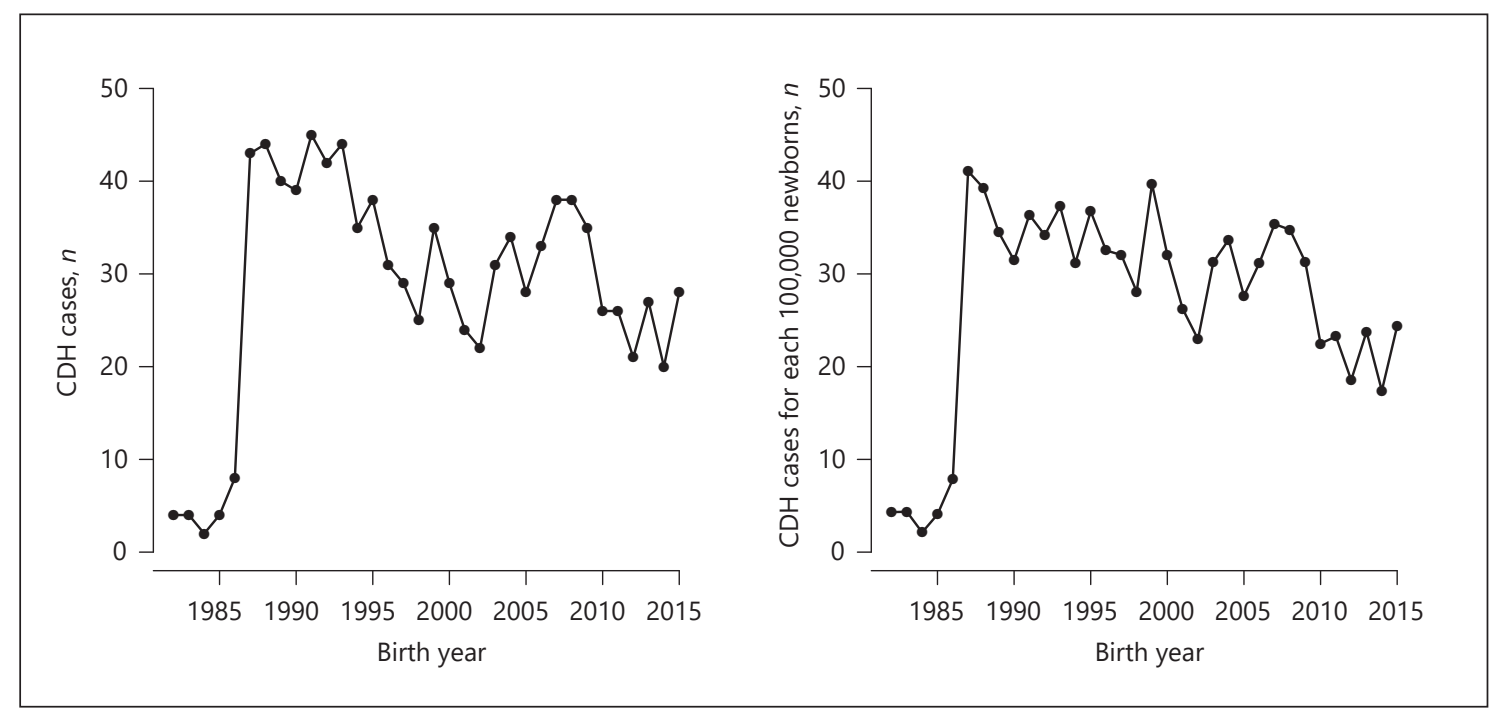

Fig. 1. Number of children born with $\mathrm{CDH}$ during the study period in Sweden.

number of children born with $\mathrm{CDH}$ in Sweden decreased during the latter part of the study period (Fig. 1a, b), probably due to the increasing number of terminations following improvements in prenatal diagnosis, as we have previously reported [12]. We did not find any association between calendar time and the incidence of CDH (Fig. 2). All the cases of $\mathrm{CDH}$ were within the same interval of days every month with the exception of the month of December. The mortality rate during the study period was $31 \%$ (304/972). Maternal age, ethnicity, parity, exposure to tobacco, BMI, IVF, previous history of spontaneous abortion or IUFD, and coexisting chronic diseases (urinary tract infection, chronic renal disease, pregestational diabetes, epilepsy, asthma, ulcerative colitis, inflammatory bowel disease, or systemic lupus erythematous) did not increase the risk of $\mathrm{CDH}$ occurring in the fetus. There was a significant association between maternal hypertension and the risk of $\mathrm{CDH}$ (OR 3.32, 95\% CI 1.41-7.79, $p=0.01$; Table 1). We did not find any changes of diagnosis of pregestational hypertension over time (Fig. 3). However, the observations with pregestational hypertension were low among cases and controls, with 9 versus 14, respectively. No association was observed between preeclampsia developing during pregnancy and the diagnosis of $\mathrm{CDH}$ in the neonate. The maternal risk factors are summarized in Table 1.

There were no differences in gender distribution, but children born with $\mathrm{CDH}$ were significantly more often delivered by planned and emergency CS. Increas-

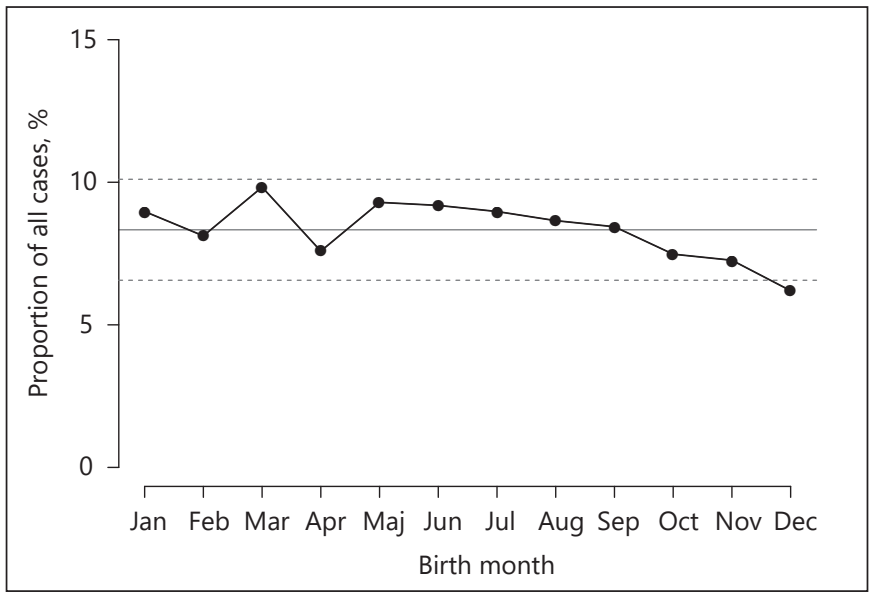

Fig. 2. Calendar time effect on the incidence of $\mathrm{CDH}$.

ing trends of CS deliveries in pregnancies with $\mathrm{CDH}$ were observed during the study period. The cases were also observed to be born at a significantly earlier GA (mean 37.6 vs. 39.1 weeks), with lower birth weights (3.01 vs. $3.52 \mathrm{~kg}$ ), were to a larger extent SGA (11 vs. $2 \%)$, and had overall lower Apgar scores at 1, 5, and 10 $\mathrm{min}$. The placental weight was also significantly lower in $\mathrm{CDH}$ babies compared to controls, but the $\mathrm{Pw} / \mathrm{Bw}$ ratio was higher in cases of $\mathrm{CDH}$ (Table 2; Fig. 4). The data on perinatal characteristics are summarized in Table 2. 
Table 1. Maternal risk factors

\begin{tabular}{|c|c|c|c|c|}
\hline & $\begin{array}{l}\text { Cases } \\
(n=972)\end{array}$ & $\begin{array}{l}\text { Controls } \\
(n=4,722)\end{array}$ & $p$ values & $\begin{array}{l}\text { Unadjusted OR } \\
(95 \% \mathrm{CI})\end{array}$ \\
\hline \multicolumn{5}{|l|}{ Maternal age } \\
\hline Mean \pm SD & $30.1 \pm 5.3$ & $29.9 \pm 5.2$ & 0.28 & \\
\hline$<20$ years & $20(2)$ & $87(2)$ & 0.49 & $1.19(0.72-1.92)$ \\
\hline 20-24 years & $151(16)$ & $756(16)$ & 0.95 & $0.99(0.8-1.23)$ \\
\hline $25-29$ years & $310(32)$ & $1,574(34)$ & & 1 \\
\hline $30-34$ years & $309(32)$ & $1,450(31)$ & 0.27 & $1.10(0.93-1.32)$ \\
\hline $35+$ years & $182(19)$ & 805 (17) & 0.17 & $1.16(0.94-1.42)$ \\
\hline Ethnicity & & & 0.113 & \\
\hline Nordic & $827(87)$ & $4,013(88)$ & n.s. & \\
\hline European & $27(3)$ & $143(3)$ & n.s. & \\
\hline Asian & $60(6)$ & $270(6)$ & n.s. & \\
\hline African & $17(2)$ & $99(2)$ & n.s. & \\
\hline North American & $5(0.5)$ & $16(0.3)$ & n.s. & \\
\hline South American & $10(1)$ & $44(1)$ & n.s. & \\
\hline \multicolumn{5}{|l|}{ Parity } \\
\hline 1 & $430(44)$ & $1,970(42)$ & & 1 \\
\hline 2 & $333(34)$ & $1,703(36)$ & 0.13 & $0.89(0.76-1.04)$ \\
\hline $3+$ & $208(21)$ & $999(21)$ & 0.49 & $0.10(0.78-1.13)$ \\
\hline \multicolumn{5}{|l|}{ BMI } \\
\hline$<18$ & $14(2)$ & $66(2)$ & 0.74 & $1.11(0.59-2.08)$ \\
\hline $18-24$ & $433(63)$ & $2,359(66)$ & 0.67 & $0.96(0.78-1.18)$ \\
\hline $25-29$ & $157(23)$ & $838(23)$ & & 1 \\
\hline $30-34$ & $57(8)$ & $232(6)$ & 0.18 & $1.27(0.9-1.8)$ \\
\hline$>35$ & $22(3)$ & $80(2)$ & 0.16 & $1.45(0.86-2.45)$ \\
\hline \multicolumn{5}{|l|}{ Tobacco exposure at conception } \\
\hline Non-smoking & $334(83)$ & $1,775(82)$ & & 1 \\
\hline Smoking 1-9 cigarettes/day & $37(9)$ & $196(9)$ & 0.87 & $0.97(0.67-1.41)$ \\
\hline$>10$ cigarettes/day & $32(8)$ & $186(9)$ & 0.47 & $0.86(0.58-1.29)$ \\
\hline Non-chewing tobacco & $395(99)$ & $2,089(97)$ & & 1 \\
\hline Chewing tobacco & $6(1)$ & $57(3)$ & 0.24 & $0.6(0.25-1.42)$ \\
\hline \multicolumn{5}{|l|}{ Tobacco exposure during second trimester } \\
\hline Non-smoking & $732(86)$ & $3,756(86)$ & & 1 \\
\hline Smoking 1-9 cigarettes/day & $83(9)$ & $389(9)$ & 0.58 & $1.08(0.83-1.39)$ \\
\hline$>10$ cigarettes/day & $39(5)$ & $236(5)$ & 0.18 & $0.78(0.55-1.12)$ \\
\hline Non-chewing tobacco & $404(98)$ & $2,201(99)$ & & 1 \\
\hline Chewing tobacco & $7(2)$ & $26(1)$ & 0.3 & $1.58(0.66-3.75)$ \\
\hline IVF & $15(2)$ & $51(1)$ & 0.25 & $1.47(0.81-2.69)$ \\
\hline Previous spontaneous abortion or IUFD & $216(22)$ & $872(18)$ & 0.1 & $1.18(0.97-1.43)$ \\
\hline \multicolumn{5}{|l|}{ Maternal chronic diseases } \\
\hline Urinary tract infection & $13(1)$ & $58(1)$ & 0.48 & $1.1(0.58-2.06)$ \\
\hline Renal disease & 0 & 3 & 0.28 & $1.78(0.79-4.01)$ \\
\hline Pregestational diabetes & $6(1)$ & $22(<1)$ & 0.61 & $1.25(0.49-3.15)$ \\
\hline Epilepsy & $8(1)$ & 26 & 0.37 & $1.67(0.74-3.77)$ \\
\hline Asthma & $42(4)$ & $206(4)$ & 0.16 & $0.94(0.66-1.33)$ \\
\hline IBD & $7(1)$ & 22 & 0.32 & $1.6(0.68-3.78)$ \\
\hline SLE & 1 & 2 & 0.43 & $2.5(0.23-27.57)$ \\
\hline Hypertension & $9(1)$ & $14(<1)$ & 0.01 & $3.32(1.41-7.79)$ \\
\hline Preeclampsia & $24(3)$ & $132(2)$ & 0.87 & $0.54(0.38-1.4)$ \\
\hline
\end{tabular}

Data are presented as $n(\%)$ or as indicated. Values in bold are significant. IUFD, intrauterine fetal demise; IBD, inflammatory bowel disease; SLE, systemic lupus erythematous. 
Fig. 3. Number of observations of pregestational hypertension among cases and controls.

Fig. 4. Correlation between $\mathrm{Pw}(\mathrm{g})$ and $\mathrm{Bw}$ (g).
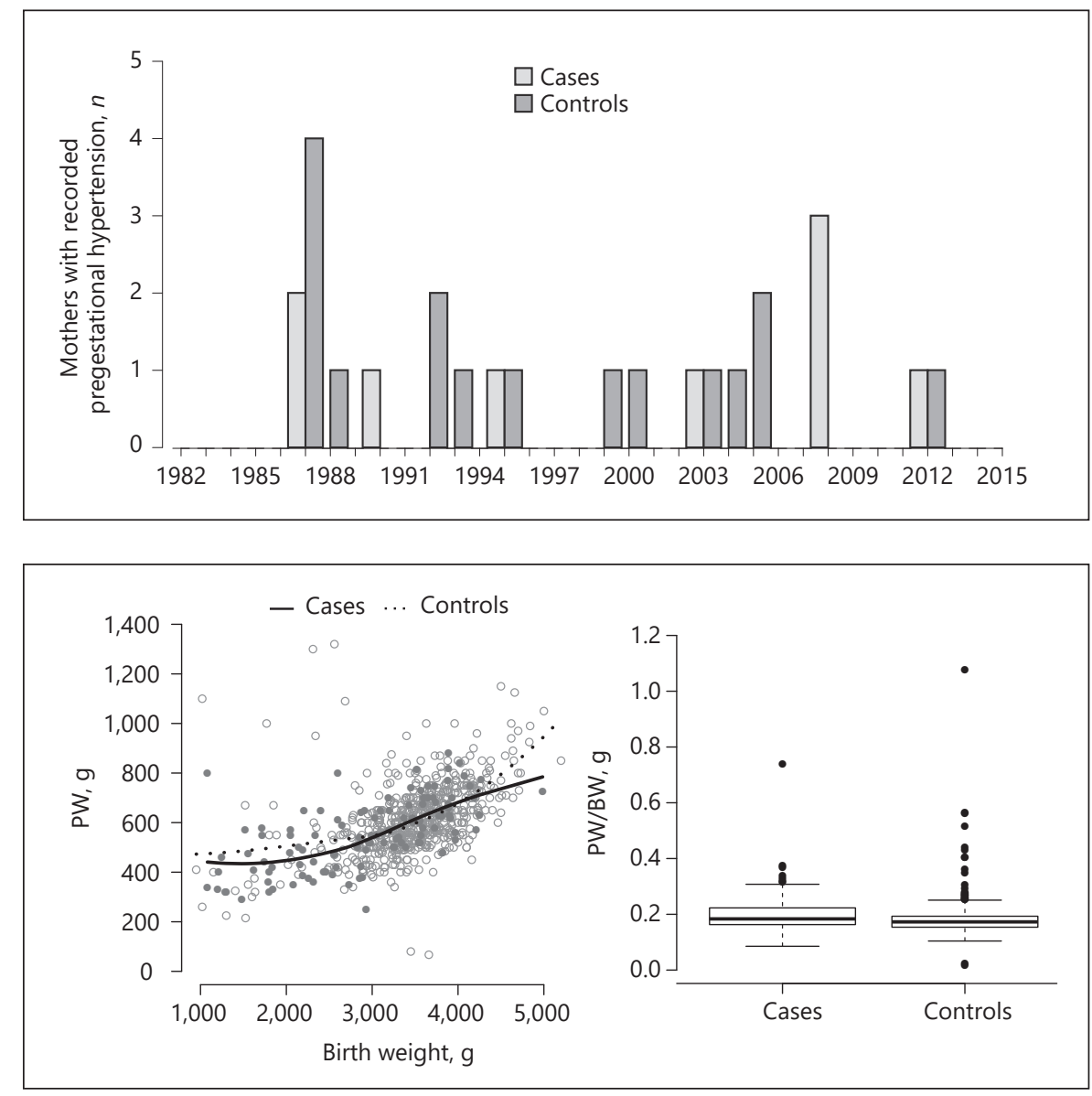

\section{Discussion}

In our study we observed that maternal pregestational hypertension was associated with a higher risk of giving birth to a baby diagnosed with $\mathrm{CDH}$, but no association was found when preeclampsia developed during pregnancy. Furthermore, we found that $\mathrm{CDH}$ patients have a lower GA at birth, and lower birth and placental weights.

To our knowledge, this is the first nationwide registerbased study exploring risk factors for $\mathrm{CDH}$. The well-established population-based medical registries in Sweden, with high validity and coverage, allow these kind of powerful studies, with prospectively collected data, and low risk of selection or information bias.

The completeness of the data, including all cases of $\mathrm{CDH}$ in the nation during the study period and follow-up through linkages among the different registries through the personalized 10-digit identification number, makes this study unique. Potential limitations of the study are the possible misclassifications of exposures or outcomes.
However, such a potential error should be similar between cases and matched controls, and thus be balanced.

The limited knowledge of the etiology of $\mathrm{CDH}$ hampers the possibility of selecting potential confounders, but by matching and stratification and performing multivariate adjust analysis we tried to control for most plausible biological confounders.

There have been previous studies that have tried to show a relationship between maternal hypertension and congenital malformations. A Danish nationwide study showed a correlation between maternal hypertension and male hypospadias and cryptorchidism [14]. Other studies have demonstrated contradictory results regarding the correlation between treatment with antihypertensive agents, for example beta-blockers and renin-angiotensin antagonists during pregnancy and the risk for congenital heart anomalies $[15,16]$, although lately a systematic review has shown an association between maternal hypertension and an increased risk of congenital heart disease in the offspring [17]. To the best of our knowledge, the 
Table 2. Perinatal characteristics

\begin{tabular}{|c|c|c|c|}
\hline & Cases $(n=972)$ & Controls $(n=4,722)$ & $p$ value \\
\hline \multicolumn{4}{|l|}{ Delivery mode } \\
\hline Vaginal & $529(54)$ & $3,450(74)$ & $<0.001$ \\
\hline \multicolumn{4}{|l|}{$\mathrm{CS}$} \\
\hline Elective & $120(12)$ & $174(4)$ & $<0.001$ \\
\hline Emergent & $74(8)$ & $202(4)$ & $<0.001$ \\
\hline GA at birth, weeks & $37.67 \pm 3$ & $39.19 \pm 2$ & $<0.001$ \\
\hline Bw, g & $3,031 \pm 803$ & $3,524 \pm 594$ & $<0.001$ \\
\hline SGA & $108(11)$ & $103(2.2)$ & $<0.001$ \\
\hline Median 1-min Apgar score (IQR) & $7(4.9)$ & $9(9.9)$ & $<0.001$ \\
\hline Median 5-min Apgar score (IQR) & $8(5.10)$ & $10(10.10)$ & $<0.001$ \\
\hline Median 10-min Apgar score (IQR) & $9(6.10)$ & $10(10.10)$ & $<0.001$ \\
\hline Pw, g & $553 \pm 141$ & $613 \pm 146$ & $<0.001$ \\
\hline $\mathrm{Pw} / \mathrm{Bw}$ ratio & $0.20 \pm 0.07$ & $0.18 \pm 0.06$ & $<0.001$ \\
\hline
\end{tabular}

observations in this study comprise the first report on the association between maternal hypertension and the risk for $\mathrm{CDH}$.

However, it remains unclear if the physiological and biological changes derived by pregestational hypertension result in a plausible molecular and embryological mechanism early in gestation that causes an increased incidence of $\mathrm{CDH}$, or if the association is a consequence of the medical treatment administered to the pregnant women for hypertension. Unfortunately, we are currently unable to answer this question with enough statistical power, since the National Swedish Registry for Drugs Prescription has only been available since 2005, and thus too few entries relevant for this study are currently available. The increasing trends of CS deliveries in pregnancies with $\mathrm{CDH}$ that were observed during the study period could probably be explained by an improved prena- tal detection rate and national strategies of planned delivery mode in pregnancies with $\mathrm{CDH}$ [18].

In conclusion, pregestational hypertension but not preeclampsia is associated with an increased risk of the fetus developing $\mathrm{CDH}$. CDH babies are born at an earlier GA, with lower birth and placental weights.

\section{Statement of Ethics}

The study was approved by the regional ethical committee in Stockholm, Dnr 2013/1550-31/3.

\section{Disclosure Statement}

The authors have no conflicts of interest.

\section{References}

1 Bielinska M, Jay PY, Erlich JM, Mannisto S, Urban Z, Heikinheimo M, et al. Molecular genetics of congenital diaphragmatic defects. Ann Med. 2007;39(4):261-74

2 Pober BR. Overview of epidemiology, genetics, birth defects, and chromosome abnormalities associated with $\mathrm{CDH}$. Am J Med Genet C Semin Med Genet. 2007 May; $145 \mathrm{C}(2): 158-71$
3 Pober BR. Genetic aspects of human congenital diaphragmatic hernia. Clin Genet. 2008 Jul;74(1):1-15

4 Caspers KM, Oltean C, Romitti PA, Sun L, Pober BR, Rasmussen SA, et al.; National Birth Defects Prevention Study. Maternal periconceptional exposure to cigarette smoking and alcohol consumption and congenital diaphragmatic hernia. Birth Defects Res A Clin Mol Teratol. 2010 Dec;88(12):1040-9.
5 McAteer JP, Hecht A, De Roos AJ, Goldin AB. Maternal medical and behavioral risk factors for congenital diaphragmatic hernia. J Pediatr Surg. 2014 Jan;49(1):34-8.

6 Felix JF, van Dooren MF, Klaassens M, Hop WC, Torfs CP, Tibboel D. Environmental factors in the etiology of esophageal atresia and congenital diaphragmatic hernia: results of a case-control study. Birth Defects Res A Clin Mol Teratol. 2008 Feb;82(2):98-105. 
7 Waller DK, Tita AT, Werler MM, Mitchell AA. Association between prepregnancy maternal body mass index and the risk of having an infant with a congenital diaphragmatic hernia. Birth Defects Res A Clin Mol Teratol. 2003 Jan;67(1):73-6.

8 Yang W, Carmichael SL, Harris JA, Shaw GM. Epidemiologic characteristics of congenital diaphragmatic hernia among 2.5 million California births, 1989-1997. Birth Defects Res A Clin Mol Teratol. 2006 Mar;76(3):170-4.

9 McGivern MR, Best KE, Rankin J, Wellesley D, Greenlees R, Addor MC, et al. Epidemiology of congenital diaphragmatic hernia in Europe: a register-based study. Arch Dis Child Fetal Neonatal Ed. 2015 Mar;100(2):F137-44.

10 Shanmugam H, Brunelli L, Botto LD, Krikov S, Feldkamp ML. Epidemiology and Prognosis of Congenital Diaphragmatic Hernia: A Population-Based Cohort Study in Utah. Birth Defects Res. 2017 Nov;109(18):1451-9.
11 Levison J, Halliday R, Holland AJ, Walker K, Williams G, Shi E, et al.; Neonatal Intensive Care Units Study of the NSW Pregnancy and Newborn Services Network. A populationbased study of congenital diaphragmatic hernia outcome in New South Wales and the Australian Capital Territory, Australia, 19922001. J Pediatr Surg. 2006 Jun;41(6):1049-53.

12 Burgos CM, Frenckner B. Addressing the hidden mortality in $\mathrm{CDH}$ : A population-based study. J Pediatr Surg. 2017 Apr;52(4):522-5.

13 Centre for Epidemiology the Swedish National Board of Health and Welfare. The Swedish Medical Birth Register - a summary of content and quality. Stockholm: EpC; 2003. Available from: http://www.socialstyrelsen. se/Lists/Artikelkatalog/Attachments/ 10655/2003-112-3_20031123.pdf.

14 Arendt LH, Henriksen TB, Lindhard MS, Parner ET, Olsen J, Ramlau-Hansen CH. Hypertensive Disorders of Pregnancy and Genital Anomalies in Boys: A Danish Nationwide Cohort Study. Epidemiology. 2018 Sep;29(5): 739-48.
15 Bergman JE, Lutke LR, Gans RO, Addor MC, Barisic I, Cavero-Carbonell C, et al. BetaBlocker Use in Pregnancy and Risk of Specific Congenital Anomalies: A European Case-Malformed Control Study. Drug Saf. 2018 Apr;41(4):415-27.

16 Fisher SC, Van Zutphen AR, Werler MM, Lin AE, Romitti PA, Druschel CM, et al.; National Birth Defects Prevention Study. Maternal Antihypertensive Medication Use and Congenital Heart Defects: Updated Results From the National Birth Defects Prevention Study. Hypertension. 2017 May;69(5):798-805.

17 Ramakrishnan A, Lee LJ, Mitchell LE, Agopian AJ. Maternal Hypertension During Pregnancy and the Risk of Congenital Heart Defects in Offspring: A Systematic Review and Meta-analysis. Pediatr Cardiol. 2015 Oct;36(7):1442-51.

18 Mesas Burgos C, Hammarqvist-Vejde J, Frenckner B, Conner P. Differences in Outcomes in Prenatally Diagnosed Congenital Diaphragmatic Hernia Compared to Postnatal Detection: A Single-Center Experience. Fetal Diagn Ther. 2016;39(4):241-7. 